\title{
PARADIGMA DA COMPLEXIDADE E TEORIA DAS ORGANIZAÇÕES: UMA REFLEXÃO EPISTEMOLÓGICA
}

COMPLEXITY PARADIGM AND THEORY OF ORGANIZATIONS: AN EPISTEMOLOGICAL REFLECTION

PARADIGMA DE LA COMPLEJIDAD Y TEORÍA DE LAS ORGANIZACIONES: UNA REFLEXIÓN EPISTEMOLÓGICA

\begin{abstract}
RESUMO
Este ensaio é produto de uma reflexão acerca da epistemologia da complexidade e sua importância para a epistemologia da administração e para a teoria das organizações. Propõe-se auxiliar na compreensão do seu surgimento, apontando sua potencial contribuição para o avanço da epistemologia da administração e da teoria das organizações. Para tanto, num primeiro momento, aborda o surgimento de uma epistemologia específica da administração e a necessidade de um novo olhar sobre ela. Em seguida, trata sinteticamente da epistemologia e do paradigma da complexidade, para então passar a discutir a relação e as contribuições potenciais desses conhecimentos para o avanço da reflexão epistemológica na administração e do aperfeiçoamento das teorias organizacionais. Por fim, destaca algumas questões que surgem a partir dessa reflexão, em se tratando da possibilidade da adoção da epistemologia da complexidade para a realização de estudos organizacionais numa perspectiva crítica.
\end{abstract}

PALAVRAS-CHAVE Paradigma, teoria da complexidade, teoria das organizações, epistemologia, pesquisa em administração.

Maurício Serva mserva@terra.com.br

Professor do Departamento de Ciências da Administração, Universidade Federal de Santa Catarina - Florianópolis - SC, Brasil

Taisa Dias taisa.adm@hotmail.com

Doutoranda pelo Curso de Pós-Graduação em Administração, Universidade Federal de Santa Catarina - Florianópolis - SC, Brasil

Graziela Dias Alperstedt gradial@gmail.com

Professora da Escola Superior de Administração e Gerência, Universidade do Estado de Santa Catarina - Florianópolis - SC, Brasil

Recebido em 14.11.2009. Aprovado em 27.05.2010

Avaliado pelo sistema double blind review

Editor Científico: Rodrigo Bandeira-de-Mello

ABSTRACT This essay is the product of a reflection on the epistemology of complexity and its importance to the epistemology of business administration and organizational theory. It is proposed to assist in the understanding of its emergence, by indicating its potential contribution to the advance of the epistemology of management and organizational theory. To do so, it first addresses the emergence of a specific epistemology of administration and the need to take a new look at it. Then, it summarizes epistemology and the complexity paradigm, and subsequently moves on to discuss the relationship and potential contributions of this knowledge to the advance of epistemological reflection in administration and in improving organizational theories. Finally, it highlights some of the issues that arise from this reflection, by considering the possibility of adopting the epistemology of complexity for carrying out organizational studies from a critical perspective.

KEYWORDS Paradigm, complexity theory, organizational theory, epistemology, administration research.

RESUMEN Este ensayo es producto de una reflexión acerca de la epistemología de la complejidad y su importancia para la epistemología de la administración y para la teoría de las organizaciones. Se propone auxiliar en la comprensión de su surgimiento, apuntando su potencial contribución para el avance de la epistemología de la administración y de la teoría de las organizaciones. Para ello, en un primer momento, aborda el surgimiento de una epistemología específica de la administración y la necesidad de una nueva forma de observarla. A continuación, trata sintéticamente la epistemología y el paradigma de la complejidad, para entonces discutir la relación y las contribuciones potenciales de esos conocimientos para el avance de la reflexión epistemológica en la administración y del perfeccionamiento de las teorias organizacionales. Finalmente, destaca algunas cuestiones que surgen a partir de esa reflexión, en cuanto a la posibilidad de adopción de la epistemología de la complejidad para la realización de estudios organizacionales en una perspectiva crítica.

PALABRAS CLAVE Paradigma, teoría de la complejidad, teoría de las organizaciones, epistemología, investigación en administración. 


\section{INTRODUÇÃO}

A ortodoxia na teoria das organizações foi desenvolvida a partir de metáforas suportadas pelo paradigma funcionalista e pelos seus pressupostos, acabando por engendrar o desenvolvimento de teorias pautadas em fundamentos pouco questionados até os anos 1980. No âmbito do paradigma funcionalista, os teóricos das organizações abordam frequentemente seu objeto a partir de uma estrutura de referências com base em pressupostos não discutidos, e, na medida em que esses pressupostos são reforçados e reafirmados continuamente por diversos pesquisadores, essa visão ortodoxa de mundo passa a ser assumida como única e inquestionável. Para Morgan, "a natureza parcial e autossustentadora da ortodoxia só se torna evidente na medida em que o teórico expõe as suposições básicas ao desafio de modos alternativos de visão, e começa a apreciar essas alternativas em seus próprios termos" (MORGAN, 2005, p. 59). Enquanto a ortodoxia se baseia nessas metáforas funcionalistas, novas metáforas que desafiam essas suposições emergem e vêm se desenvolvendo no sentido de ofertar vias alternativas para a teoria das organizações.

Burrel e Morgan (1979), atentos a isso, exploraram o papel dos paradigmas como visões da realidade social e argumentaram que a teoria social de maneira geral e a teoria das organizações de maneira particular poderiam ser analisadas a partir de quatro amplos conjuntos de visões de mundo, divergindo sobre a natureza da ciência (objetiva/ subjetiva) e a natureza da sociedade (regulação/mudança radical). Desse mapeamento, os autores identificaram então quatro paradigmas: funcionalista, interpretativista, humanista radical e estruturalista radical, cada qual contendo teorias de certa forma relacionadas, diferenciadas na abordagem e na perspectiva, porém compartilhando suposições fundamentais sobre a natureza da realidade de que tratam.

O conceito de paradigma remete-nos à ideia básica de Thomas Kuhn (1987), que o concebe como uma premissa fundamental entre os pesquisadores que o compartilham. É a visão de mundo que assegura a uma comunidade científica suas abordagens de investigação científica. Nesse sentido, pesquisadores que compartilham do mesmo paradigma foram submetidos a uma iniciação profissional e educação similares, absorvendo a mesma literatura técnica e retirando dela as mesmas lições.

As ideias de Kuhn são especialmente importantes, pois permitem a compreensão das forças impulsionadoras e restritivas de novas teorias e ideias. Ao questionar o enfoque tradicional do progresso científico, revela que a ciência está em constante estado de evolução. Essa verdadeira evolução ou progresso da ciência ocorre de forma descontínua, quando um paradigma é substituído por outro. É o que Kuhn denomina "revolução". Ela se inicia quando o paradigma instaurado já não consegue dar explicações acerca dos fenômenos estudados.

Com uma concepção particular, Morin (1996) conceitua paradigma como "um tipo de relação muito forte, que pode ser de conjunção ou de disjunção, logo, aparentemente de natureza lógica, entre alguns conceitos mestres". Essa relação dominadora "determina o curso de todas as teorias, de todos os discursos que o paradigma controla. O paradigma é invisível para quem sofre os seus efeitos, mas é o que há de mais poderoso sobre as suas ideias" (MORIN, 1996, p. 31). Tais abordagens acerca do conceito de paradigma são essenciais para explicar a distância entre o paradigma funcionalista, ainda prevalecente nos estudos organizacionais, e o paradigma da complexidade proposto neste artigo.

Complexidade, paradigma da complexidade, teoria da complexidade, paradigma emergente, ciência nova ou nova aliança são termos que vêm sendo lidos, ouvidos, defendidos, criticados e reconhecidos por muitos pesquisadores, e, em alguns casos, com carência de fundamentação de seus princípios e pressupostos. Na interação com pesquisadores experientes e conhecedores do tema e também com iniciantes que já se lançam à pesquisa fazendo uso dessa teoria, foi possível concluir dois aspectos: a) ao falar desse paradigma, surgem dúvidas, confusões e até certa inibição, pelo risco da sua aplicação inconsistente; e b) a noção incipiente das possibilidades do seu uso em pesquisa social não tem sido freio para a geração de grupos de pesquisas, cujos projetos têm a perspectiva de se utilizarem do seu sistema de ideias, seja enquanto teoria, paradigma ou simples atitude.

Assim sendo, um dos objetivos do presente ensaio é contribuir para uma reflexão acerca das prováveis relações entre a epistemologia da complexidade, a epistemologia da administração e a própria teoria das organizações. Ao apresentar o produto de uma reflexão acerca da epistemologia da complexidade, ampliam-se os objetivos do ensaio, destacando a sua importância para a epistemologia e a teoria das organizações. Seu intuito é promover uma melhor compreensão da epistemologia da complexidade de maneira a permitir a ampliação do entendimento sobre a forma como essa epistemologia emergiu e como se estabeleceu, consolidando um paradigma, e em seguida indicar a sua contribuição potencial para o avanço da epistemologia da administração. Para tanto, discute o surgimento de uma epistemologia da administração e a necessidade de um novo olhar sobre as teorias organizacionais. 
Para atingir tais objetivos, primeiramente aborda-se o surgimento de uma epistemologia específica da administração. Em seguida, trata-se sinteticamente da epistemologia e do paradigma da complexidade, para, então, discutir a relação e as contribuições potenciais desses conhecimentos com o avanço da reflexão epistemológica na administração e do aperfeiçoamento das teorias organizacionais. Por fim, são levantadas algumas questões enfrentadas ao se adotar a epistemologia da complexidade para a realização de estudos organizacionais numa perspectiva crítica.

\section{O SURGIMENTO DE UMA EPISTEMOLOGIA ESPECÍFICA DA ADMINISTRAÇÃO}

A epistemologia se propõe a definir tanto uma teoria geral do conhecimento como um estudo mais limitado acerca da gênese e estrutura das ciências. Seu conceito não tem um significado rigoroso e único, mas apesar disso, como se apresenta com caráter interdisciplinar, permite ao pesquisador construir uma ideia sobre a sua própria disciplina. Nesse sentido, Japiassu (1991, p. 16-17) se refere a três tipos de epistemologia, quais sejam, a epistemologia global ou geral - quando se refere ao saber globalmente considerado, seja este especulativo ou científico; a epistemologia particular - quando se relaciona a um campo particular do saber, seja este especulativo ou científico; e a epistemologia específica - quando se refere ao estudo próximo, detalhado e técnico da organização, do funcionamento e das possíveis relações que uma disciplina, enquanto unidade de saber científico, mantém com outras disciplinas.

Fazendo uso dessa classificação, entende-se a epistemologia da administração como uma epistemologia específi$\mathrm{ca}$, que se consolidou como saber interdisciplinar. Apesar disso, Chevalier e Loschak (1980) - dois dos primeiros autores a empreender uma discussão essencialmente epistemológica na administração -, ao indicarem que a ciência da administração é uma ciência social ainda em gestação, cujo objeto não é uma realidade dada e pronta para ser estudada, afirmam que ela necessita ser reconstruída a luz de uma problemática teórica específica e que, para responder aos critérios de cientificidade, deve não só superar certo número de obstáculos epistemológicos, mas também desenvolver instrumentos de análise adequados.

Desse modo, esses autores, ao revisitarem as origens da administração (principalmente da administração pública) como função de dominação utilizada por parte do Estado, argumentam acerca da dificuldade de transpor os princípios sob os quais essa ciência foi construída - especialização, profissionalização, hierarquização, dentre outros para outros tipos de organizações que não o Estado. Por considerar que nenhuma sociedade é capaz de subsistir sem um princípio de unidade e de coesão estrutural, os mesmos modelos que servem ao Estado são aplicados no interior de outras organizações. Para esses autores, a causa dessa dificuldade tem seu "mal de origem" no momento em que a administração se apropriou de princípios desenvolvidos para a sociedade que levam em conta aspectos políticos, culturais e econômicos. Em seguida, Chevalier e Loschak (1980) enfatizam os obstáculos epistemológicos que devem ser superados para se reconstruir a ciência da administração, a saber: o parasitismo ideológico, o normativismo e as armadilhas do empirismo. Essas diferentes atitudes caracterizam-se por uma recusa em romper com a vivência cotidiana e as representações que ela veicula, gerando uma confusão entre realidade percebida e realidade científica que impede a interrogação sobre o porquê das coisas. Segundo eles, qualquer tentativa de explicação requer não só uma vigilância epistemológica constante $e$ destinada a superar os obstáculos que entravam o acesso ao conhecimento científico, mas também uma reflexão concomitante sobre os métodos, os conceitos e as técnicas mais adaptadas para atingir o objetivo visado.

A ciência da administração pode utilizar os conhecimentos oriundos de outras ciências a fim de alargar e apurar sua problemática, enriquecer os seus instrumentos conceituais e aperfeiçoar suas técnicas de investigação. Para desenvolver essa proposta, Chevalier e Loschak (1980) enfocam três princípios fundamentais: 1) uma abordagem integrativa - cabe à ciência administrativa integrar as diferentes disciplinas que a compõem, não implicando sua síntese, mas estabelecendo os diversos aspectos que compõem a análise das organizações; 2) instrumentos conceituais - a fim de escapar das armadilhas do formalismo jurídico, a ciência da administração deve recorrer ao aparelho metodológico elaborado em outras ciências; 3) meios de investigação - a fim de alimentar a sua reflexão teórica, a administração deve utilizar ao máximo as investigações empíricas, pois sem elas os conhecimentos dessa ciência seriam apenas especulações intelectuais.

Audet e Déry (1996) abordam a formação epistemológica da administração partindo das teorias cientificistas de Taylor e Fayol, impulsionadas pela Revolução Industrial e, principalmente, pela Segunda Guerra Mundial. O campo da Administração surge, durante a Segunda Revolução Industrial, no bojo do discurso cientificista, com a organização científica do trabalho de Taylor (as leis empíricas) e de Fayol (princípios lógicos). Esses autores teriam formado a primeira camada de sedimentação do conhecimento científico da administração, e os demais autores que lhes seguiram até os anos 1930 estiveram mais aten- 
tos a resultados práticos e por isso não teriam tido muita sensibilidade ao movimento que ocorria na epistemologia geral, como, por exemplo, o importante movimento do chamado Círculo de Viena.

Audet e Déry também reconhecem que a Segunda Guerra Mundial proporcionou um ambiente propício ao desenvolvimento da administração por dois principais motivos: a adoção de regras de exceção que permitiram uma administração mais gerencial dos estados-nação, estes atuando como "megaempresas", e, em segundo lugar, a aplicação de diversos conceitos militares, tais como tática, estratégia, campo de atuação e logística. Nesse período, denominado por Audet e Déry "cientificização das práticas", a administração aborda o trabalho formal, começando então a fazer eco às posições anteriormente defendidas pelo Círculo de Viena e passando assim a discutir regras de produção e validação do conhecimento. A epistemologia da administração que se forma nesse período nasce neopositivista, e a epistemologia local, formal e explícita da época projeta as ciências da administração numa imagem de ciência unitária. Com essa característica positivista, a ciência da administração, ao mesmo tempo que gera unidade, exclui aqueles que não aceitam se submeter a tal ortodoxia científica. Tempos depois, a ruptura com o cientificismo pragmático ocorre, e novos membros do campo da administração reinvindicam o status de ciência social aplicada.

No início dos anos 1970, surge então uma epistemologia historiográfica e sociológica, e isso vai se refletir em todos os campos da produção científica, inclusive na administração. Esse processo conduziu a uma série de consequências, a saber: as práticas remetem a regras de produção e validação do conhecimento muito diferentes; fica evidente o caráter polimorfo da administração; a legitimação dessas diferenças internas geram subunidades dentro do campo da Administração. Essas consequências afetam diferentemente os membros do campo, e a epistemologia da administração torna-se cada vez mais local, explícita, empírica e pluralista (AUDET; DERY, 1996).

Campos (1993), ao abordar a retomada da relevância das pesquisas científicas em administração, destaca três limitações que o paradigma dominante promoveu em relação ao desenvolvimento das teorias da administração: o reducionismo, a incompetência para lidar com contradições e a não apreciação da subjetividade, da capacidade essencial do ser humano de interpretar a realidade. A combinação dessas três limitações teria dado origem à racionalidade instrumental tomada como lógica da vida, ao comportamento organizacional como ação humana, ao lucro como rentabilidade, à produtividade como autorrealização, à eficiência como relevância organizacional e ao emprego como trabalho. Como solução para esse hiato, Campos propõe uma abordagem dialética como forma de permitir as contradições e, assim, superá-lo.

Garcia e Bronzo (2000), ao confrontarem os pressupostos da racionalidade na ciência moderna com os traços da nova racionalidade, identificam três questões que, segundo eles, deveriam dar a direção ao processo de reconstrução dos caminhos para o estudo das organizações, a saber: 1) a intensificação da globalização e a revolução da base tecnológica a partir da década de 1970; 2) o descolamento entre a economia real e a especulação financeira no nível mundial; e 3) a importância de aproximar os estudos organizacionais das contribuições recentes no bojo da teoria da firma, num âmbito microeconômico. Baseados nessa identificação, os autores sustentam que o alcance de tais estudos poderia aumentar a partir de um olhar, mais distante, aos aspectos normativos e hegemônicos funcionalistas. Consequentemente, os autores fazem referência a uma racionalidade substantiva que viria requerer a consideração conjunta das perspectivas histórica, crítica, plural e dialética. Garcia e Bronzo (2000) finalizam criticando a consagração da visão mecanicista do mundo, evidenciada ao se tentar entender a ciência e o seu progresso.

Ao analisar o fato organizacional como objeto de estudo, Serva (2001) faz referência a Guerreiro Ramos, Mauss e Durkheim, apontando para uma possibilidade de ampliação dos horizontes da teoria das organizações. $O$ autor destaca que as ligações entre as organizações e a sociedade são complexas, além de marcadas pela causalidade mútua e que, dessa forma, apenas uma abordagem dialética poderia concebê-las satisfatoriamente, já que, se o fato organizacional é fato histórico e cultural, o primeiro se submete a um determinado contexto histórico e, consequentemente, às dimensões de tempo, espaço e cultura.

Revisitando a ótica dialética de Demo (1985), a superação de uma realidade social é um passo normal na direção da construção da história, uma vez que toda sociedade pode gerar sua superação. Por conseguinte, a reconstrução epistemológica da administração proposta por Chevalier e Loschak (1980), e endossada por outros autores, parece viável e necessária como forma de consolidar a cientificidade da produção dos conhecimentos nesse campo.

\section{UM NOVO OLHAR EPISTEMOLÓGICO NA ADMINISTRAÇÃO}

A partir do entendimento histórico, ainda que breve, do surgimento de uma epistemologia da administração e da sua consolidação como saber interdisciplinar, busca-se 
a compreensão de um novo olhar epistemológico sobre a administração, a partir do estudo da racionalidade nas organizações e de uma abordagem substantiva sobre elas.

Nos anos 1980, portanto no mesmo período do estudo de Chevalier e Loschak, Guerreiro Ramos abre uma importante discussão epistemológica no campo da administração. Para o autor, não aconteceram mudanças significativas na teoria das organizações no que tange aos pressupostos epistemológicos desde Taylor (que limitou seus estudos a questões técnicas) e Simon (que negligenciou os limites das regras de cognição inerentes às organizações econômicas), e dentre as limitações dessas abordagens, destaca que: 1) o conceito de racionalidade predominante na teoria das organizações conduz ao entendimento de que o comportamento econômico constitui a totalidade da natureza humana; 2) ela não distingue o significado substantivo do significado formal da organização; 3) não trabalha com a ideia clara do que compreende a interação simbólica no conjunto dos relacionamentos interpessoais e, ainda; 4) se apoia no pressuposto de que o homem é apenas um componente da força de trabalho, participando como item de custo.

Assim, Guerreiro Ramos (1989) evidencia a emergente necessidade de uma reformulação epistemológica na teoria das organizações, indicando que ela tende a sobreviver apenas se vier a se transformar e se propuser como uma teoria viável, uma vez que, como afirmado por ele, o homem tem diferentes tipos de necessidades e a sua satisfação requer vários tipos de cenários sociais. O sistema de mercado só atende a alguns desses tipos de necessidades humanas, e, por isso, o autor acredita que "o comportamento administrativo é conduta humana condicionada por imperativos econômicos" (GUERREIRO RAMOS, 1989, p. 136). Destaca, ainda, que diferentes categorias de tempo e espaço vital, além de diferentes sistemas significativos, reportam-se a diferentes cenários sociais, e que estes, por sua vez, requerem um tecido organizacional que considere a inter-relação desses aspectos para então sustentar a abordagem substantiva em seus planejamentos.

Como tentativa de prover uma alternativa ao referido modelo de análise empregado na administração e no planejamento de sistemas sociais, que considera o mercado como a principal categoria para a ordenação dos negócios pessoais e sociais (unidimensional), Guerreiro Ramos (1989) apresenta o que ele chama de "modelo multidimensional" que considera: 1) a sociedade como um conjunto de encraves onde o mercado é apenas um deles; e 2) um sistema de governo social capaz de formular e programar, de maneira ótima, boas políticas e decisões para gerenciar esses encraves sociais. Por outro lado, ao mesmo tem- po que sugere que o "paradigma paraeconômico" é um meio de multidimensionar a análise organizacional, não considera isso tarefa fácil, uma vez que ele próprio afirma que "a atualização humana é um esforço complexo" (GUERREIRO RAMOS, 1989, p. 143).

$\mathrm{Na}$ tentativa de dar continuidade à proposta de Guerreiro Ramos, Serva (1997a; 1997b) estabelece uma relação de complementaridade entre a abordagem substantiva (Guerreiro Ramos) e a teoria da ação comunicativa (elaborada por Habermas). Mediante tal procedimento, visa demonstrar o emprego da racionalidade substantiva na gestão de organizações produtivas, abrindo novos horizontes empíricos para o desenvolvimento da abordagem substantiva lançada por Guerreiro Ramos. Serva (1997b), ao tentar demonstrar a exequibilidade da racionalidade substantiva na gestão, conclui que é preciso avançar ao mesmo tempo a teoria e a sua prática. Entende-se que, do ponto de vista epistemológico, essa tentativa somase às propostas de Guerreiro Ramos (1989), de Campos (1993) e de Garcia e Bronzo (2000) - a reconciliação do conhecimento científico com o bem-estar da sociedade e, em particular, a reconstrução epistemológica da teoria das organizações -, na medida em que a ciência administrativa também contribui para uma maior compreensão da diversidade humana, tanto individual quanto social.

Assim, os estudos voltados para a sedimentação de paradigmas emergentes podem, então, auxiliar significativamente a redução das dificuldades epistemológicas estruturais existentes na teoria das organizações. Com base nesta premissa, empreende-se a seguir uma síntese do paradigma da complexidade enquanto paradigma emergente para, numa seção subsequente, indicar sua potencial contribuição para a renovação das bases epistemológicas da teoria das organizações.

\section{NOTAS SOBRE A EPISTEMOLOGIA E OS ESTUDOS DA COMPLEXIDADE}

Uma filosofia ou conhecimento que conduza à reflexão sobre diversas teorias científicas, que não seja excludente e que não outorgue a apenas uma ciência o saber absoluto é o sentido do discurso de Descamps (1991) ao longo do desenrolar de ideias apresentadas por filósofos contemporâneos na França, no período de 1960 a 1985. Descamps utiliza-se das ideias do filósofo Michel Serres, comparando-as aos pensamentos de diversos outros filósofos contemporâneos, para demonstrar que a filosofia deve ser capaz de revelar e romper isomorfismos. Nesse sentido, entende que nenhuma disciplina poderá outorgar a si pró- 
pria um lugar de onde deduzir um saber absoluto e final.

Essa interrogação acerca da cientificidade corrobora a ideia da inexistência de uma ciência pura. Descamps recorre às reflexões de Edgar Morin para discorrer sobre o "caráter científico da ciência", no sentido de que a natureza não é somente um domínio a conquistar. Surge a necessidade de a ciência entender que seu progresso acontece por meio da filosofia e que, portanto, é preciso que os filósofos contemporâneos leiam-se uns aos outros e discutam entre si. O ruído dessa discussão, dessa desordem, é que leva a uma nova ordem, a um conhecimento novo. Nesse contexto, Morin (1982, p. 78) afirma que "o conhecimento deve tentar negociar com a incerteza [...] o trabalho com a incerteza perturba muitos espíritos, mas exalta outros [...] o trabalho com a incerteza incita o pensamento complexo [...]".

Prigogine e Stengers (1997), na obra A nova aliança, empreendem uma reflexão crítica sobre a ciência e as suas transformações. Os autores criticam a busca de leis que enquadrem a natureza em descrições matemáticas e princípios deterministas. A origem dessa concepção criticada por eles é o "mundo celeste aristotélico", que desencanta o mundo e, ao mesmo tempo, o torna "divino", negando a sua diversidade e o devir natural. Utilizam o exemplo da perda de energia na termodinâmica para mostrar que nem tudo é reversível e, a partir desse exemplo, retomam os pré-socráticos, para os quais a inteligibilidade e incerteza eram inseparáveis.

Tanto na mecânica quântica quanto na relatividade ou na dinâmica, as demonstrações de impossibilidade das certezas absolutas indicam que não se pode descrever a natureza do exterior como simples expectador. Para Prigogine e Stengers, não há verdade absoluta e sim uma "verdade na situação", além do que acreditam que a metamorfose das ciências contemporâneas não é necessariamente uma ruptura total com outros saberes, pois tais metamorfoses podem levar à compreensão dos saberes e de práticas antigas que a ciência moderna "redescobre" e que não pode negar.

A obra de Edgar Morin visa, dentre outros objetivos, ao questionamento da oposição entre fatos e natureza, contribuindo para a reflexão acerca do sentido, dos valores e das "verdades" concernentes à ciência. Para o autor, a própria ciência forjou, durante muito tempo, homogeneidades simplificadoras. Com muita frequência, os objetos foram isolados do seu contexto e do contexto dos observadores, $\mathrm{e}$, assim, as disciplinas foram fragmentadas, inviabilizando o diálogo entre as ciências. Essas reduções unificaram, quantificaram e desprezaram o que era diferente, e, mesmo reconhecendo que foi isso que permitiu avanços no conhe- cimento, como, por exemplo, do átomo e a da molécula, deve-se também reconhecer a desconsideração do acaso e da contingência nos fenômenos estudados.

As pesquisas contemporâneas vêm promovendo a percepção da importância de reintroduzir o observador na observação e a ideia de que a ciência não deve se conformar em apenas ampliar o objeto, mas sim mostrar-se capaz de estudar a si mesma, de confrontar ideias já concebidas e de postular o homem como unidade (MORIN, 1996).

Morin (1991) retoma a discussão sobre a noção de paradigma e, embora elabore uma crítica ao conceito elaborado por Kuhn, ressalta seus pontos fortes e reconhece a sua importância. Para Morin (1991), Kuhn deu ao termo "paradigma" um sentido simultaneamente "forte e difuso". A força do conceito estaria centrada no valor radical de orientação metodológica, como também de esquemas fundamentais de pensamento e de crenças. Por outro lado, o seu caráter difuso correria por conta da oscilação entre diversos sentidos, cobrindo de maneira vaga a agregação grupal de cientistas a uma dada visão de mundo. Morin contribui para o debate sobre paradigmas, ampliando significativamente o seu sentido. Para o autor, "o paradigma institui as relações primordiais que constituem os axiomas, determinam os conceitos, comandam os discursos e/ou teorias. [...] O paradigma é inconsciente, mas irriga o pensamento consciente, controla-o, e, nesse sentido, é também sobreconsciente" (MORIN, 1991, p. 190). Morin concebe o paradigma sob um ponto de vista mais amplo, para além da ciência em si, revelando-se como uma espécie de grande matriz do pensamento. No caso do Ocidente, essa matriz diz respeito aos desenvolvimentos da técnica, do capitalismo, da indústria, da burocracia, da vida urbana, tendo algo de paradigmaticamente comum entre os princípios de organização da ciência, da economia, da sociedade e do estado-nação. Nessa perspectiva, a noção de paradigma é apresentada por Morin de forma bem mais ampla: uma matriz de pensamento que comanda a civilização ocidental, na qual se insere a própria ciência. É dessa forma que Morin busca explicar como grupos de cientistas aderem a um paradigma. Não obstante a ampliação operada no conceito de paradigma, o próprio Morin continua a utilizá-lo para analisar a ciência e suas transformações, ao trabalhar insistentemente a oposição entre o paradigma da disjunção e o paradigma da complexidade. É justamente nessa dimensão de análise que se insere a análise proposta no presente trabalho.

Trazendo essas novas ideias, o paradigma da complexidade tem suas raízes históricas em pesquisas desenvolvidas no Biological Computer Laboratory, na Universidade de Illinois, onde foi desenvolvido um texto conhecido 
como On Self Organizing Systems and Their Environments, de autoria de Heinz von Foerster, em 1960 (SERVA, 1992). O referido texto foi resultado dos estudos desse autor sobre determinados temas, tais como: causalidade circular, autorreferência e o papel organizador do acaso, fazendo uso da aproximação de conhecimentos da biologia e da cibernética para abordar a dinâmica operacional dos sistemas auto-organizadores.

Na continuidade dos estudos que abordam tal temática, promoveu-se a descoberta do que foi chamado de "programa genético" na biologia e permitiu um melhor entendimento da gênese da vida, quando se comprovou que a ela se sustenta nos mecanismos físico-químicos, direcionando, então, o funcionamento da célula como se esta fosse uma "máquina viva", no sentido de que ela se autoconstrói. É nesse momento histórico - meados do século passado que se observa a contribuição da então nova teoria da comunicação, quando se faz uso dos seus termos e conceitos (programa, código, informação, mensagem, tradução, entre outros) para se entender esse novo modo de compreensão do funcionamento da célula. Pode-se dizer, então, que aí foi deflagrada a ideia de transdisciplinaridade que viria a ser fomentada pelo paradigma da complexidade. O avanço da microfísica vai deixando para trás a mecânica racional, até então muito próxima da física newtoniana, e parte para a compreensão do "complexo", incentivada pela teoria das estruturas dissipativas, que rendeu a Ilya Prigogine o Prêmio Nobel de Química em 1977, como resultado das pesquisas desenvolvidas pela Universidade Livre de Bruxelas acerca da termodinâmica do desequilíbrio.

Nessa mesma época, Jaques Monod, André Lwoff e François Jacob ensejaram uma "cibernética microscópica", quando estudaram o funcionamento e a reprodução da célula, extrapolando os limites da bioquímica celular. Esses pesquisadores desenvolveram em paralelo um estudo epistemológico em busca da renovação da ciência e destacaram a importância do acaso para a evolução das espécies. Esse segundo momento foi marcado pela publicação de O acaso e a necessidade, em 1970, pelo então líder das pesquisas, Jaques Monod, o qual já tinha sido laureado com o Prêmio Nobel de Fisiologia em 1965.

Em busca da concretização da transdisciplinaridade científica e filosófica, proporcionando a interação entre fenomenologia, dialética e teoria dos sistemas e as obras de Cornelius Castoriadis, René Girard e Ivan Illich, Edgar Morin reforça a construção desse paradigma emergente e delineia a ideia de autonomia - conceito esse relacionado à reação dos indivíduos à padronização excessiva colocada pela sociedade. Assim como o conceito de autonomia, vários outros são elaborados e consubstanciam o paradigma da complexidade, cabendo destaque aqui à organização, auto-organização, ordem, desordem e evento. De acordo com Morin (1982), é necessário considerar que sempre por trás da ordem e da organização, existe a desordem marcada pelas incertezas, ou seja, a organização não pode ser reduzida à ordem, embora a comporte e a produza (MORIN, 1982, p. 73). Portanto, se por um lado a desordem coopera na geração da ordem organizacional, por outro ela ameaça a ordem com a desintegração, seja por fatores externos ou internos.

Ainda no que se refere aos conceitos peculiares do denominado paradigma da complexidade, deduz-se então que auto-organização é o conceito central desse paradigma. No campo da cibernética, a auto-organização é tida como o conceito que deflagrou as primeiras pesquisas sobre complexidade, apesar de ter sido nas pesquisas acerca da biologia molecular (metáfora do programa genético ou máquina viva) que o conceito se percebe desafiador, o que leva ao entendimento de que se fundamenta no estudo dos sistemas vivos.

Varela (1989), partindo da ideia de um programa que programa a si próprio, conceitua então a autopoiese. O autor buscou esclarecer o seu mecanismo de auto-organização a partir da lógica de funcionamento interno dos sistemas autoprodutores, relacionando auto-organização com autonomia. A partir disso, o conceito de autonomia supõe a ideia inicial de um comportamento próprio, ou seja, de um sistema se definindo a partir de seus próprios comportamentos e em seguida ensejando a interação com o ambiente para dar conta da sua identidade.

Para Morgan (1996), a interação de um sistema com seu ambiente é um reflexo e parte de sua própria organização, o que leva ao entendimento de que o ambiente não está dissociado do sistema, sendo, na verdade, parte dele. Dessa forma, a ideia de complexidade deve dar conta do paradoxo autonomia e dependência sem se apoiar na exclusão de qualquer desses termos. Consequentemente, Morin (1982, p. 77) afirma que "[...] temos de aprender a pensar conjuntamente ordem e desordem. Sabemos vitalmente trabalhar com o acaso [...] Aprendemos, estatisticamente, de forma diversa, a trabalhar com a álea. Temos de ir mais longe". Com isso, é possível compreender que o universo precisa ser concebido a partir de uma dialógica, cada parte chamando outra parte, cada uma precisando da outra para se constituir, cada um inseparável do outro, cada um complementar do outro, mesmo que antagonista. Adicione-se a isso a ideia de que um mundo absolutamente determinista e um mundo absolutamente aleatório excluem totalmente, um e outro, o espírito humano que o observa (MORIN, 1982). É preciso misturar esses dois 
mundos que se excluem para conceber o novo mundo.

A compreensão do novo mundo passa, necessariamente, pelo conceito de evento ou acontecimento, uma vez que todos os conceitos anteriormente aqui destacados têm relação com o acaso, corroborando o princípio fundamental do paradigma da complexidade, que é o afastamento do determinismo. Para Morin, existe uma relação direta entre o número de eventos e a capacidade que um sistema tem de absorvê-los e, por meio da autoorganização, evoluir. Assim sendo, um sistema é tão ou mais complexo quanto maior for sua capacidade de absorção desses eventos. A complexidade, segundo Morin, traduz-se sempre, para um observador, em incerteza. Este já não se encontra diante de um objeto bem determinado, submetido a leis simples e sobre o qual ele pode operar previsões precisas. Essa incerteza deriva de algumas características: incomensurabilidade das interações entre as unidades elementares, caráter irregularmente aleatório que o sistema auto-organizador apresenta ao observador e o fato de que a auto-organização é capaz de evoluir.

Assim, os estudos de Morin levam aos princípios e características do paradigma da complexidade, fazendo referência sempre às noções de ordem, desordem, organização, integração e desintegração. Segundo o autor, enquanto a antiga ciência unidimensional previa um único método para todas as ciências, a nova ciência transdisciplinar estrutura-se por meio da comunicação do conhecimento físico, biológico e cultural. A complexidade consiste na contínua autoprodução, auto-organização e autonomia dos sistemas. Os princípios sobre a complexidade explicam o paradigma e dão estrutura aos tipos de lógica que o compõem: lógica probabilística, dialógica, dialética e generativa - esta última não no sentido linear e sim num sentido arborescente, que considera o todo. A lógica da vida é arborescente, e é por ser arborescente que a evolução apresenta um caráter não linear - lógica do não previsto, do inesperado e da aceitação das contradições.

Segundo Campos (1993), a compreensão da história humana requer uma abordagem dialética como forma de abrir espaço a contradições. Pelo paradigma dominante expresso no positivismo e no funcionalismo - as mentes cartesianas tendem a opções exclusivas e inadequadas para abordar problemas divergentes. Por essa razão, a autora sugere uma revolução científica ao mesmo tempo que reconhece a dificuldade em realizá-la, uma vez que o processo não é mecânico e requer alterações e deslocamentos paralelos de valores e atitudes sociais e culturais já enraizados pelo paradigma em declínio.

Morin, ao abordar o problema epistemológico da complexidade, inicia seu discurso falando do tratamento que se dá ao pensamento da complexidade: "É surpreendente que essa problemática não tenha verdadeiramente emergido nem na epistemologia nem no que se pode chamar filosofia das ciências" (MORIN, 1996, p. 13). Segundo ele, a complexidade não deve ser compreendida apenas como complicação, como normalmente é abordada.

Dois aspectos são colocados nesse contexto: a existência de uma comunidade científica (consenso), bem como a rivalidade e o conflito. Com isso, conclui-se que seja necessária uma tradição crítica dentro da própria comunidade para que ela funcione. Nesse sentido, o autor passa a discutir a intersubjetividade inerente à própria objetividade, que é incessantemente autoproduzida e reconstruída por um dinamismo específico das condições organizacionais da comunidade científica. Ou seja, a objetividade não exclui o espírito humano, o sujeito individual, a cultura, a sociedade (MORIN, 1996). Nas condições bioantropológicas do conhecimento, está o pensamento de uma auto-organização inerente aos seres vivos, com um fim em si mesmo. O cérebro e sua complexidade, por exemplo, são, ao mesmo tempo, abertos e fechados. Nele são geradas as representações, as organizações, e se compõem as percepções. A sua concepção de epistemologia complexa parece remeter à necessidade de observação das lacunas, no sentido de aproximar as instâncias separadas.

\section{REFLEXÕES SOBRE A COMPLEXIDADE, A EPISTEMOLOGIA DA ADMINISTRAÇÃO E A TEORIA DAS ORGANIZAÇÕES}

O advento da adoção dos princípios da complexidade parece ter fomentado profundas transformações no desenvolvimento científico dos últimos 40 anos, tanto nas ciências da vida, como a biologia e a fisiologia, como nas ciências mais tradicionais, como a física e a química, e também nas ciências humanas. Nestas últimas, parte da mudança está relacionada fundamentalmente com o fato de se considerar a importância do indivíduo para a dinâmica social e trazer para o centro da discussão o próprio sujeito, como produto e produtor da realidade social.

Mas há que se dar destaque a uma perspectiva surgida a partir dessas transformações, conforme fica evidenciado pelo exame dos textos que serviram de base a este ensaio: a interdisciplinaridade associada à pluralidade. Numa tentativa de resgatar o que a fragmentação ocorrida ao longo dos anos provocou em várias de suas subáreas de conhecimento, as ciências voltam a se unir para viabilizar uma compreensão da realidade social. As ciências sociais 
viram surgir uma grande diversidade de abordagens, como destacado por Berthelot (2001), o qual admite a existência de dois polos extremos coexistindo e perpassando as mesmas disciplinas e gerando várias correntes: um positivista e outro textualista ou construtivista, ou, ainda, relativista. Essa coexistência provoca a iminência de um terceiro polo, intermediário, que viria permitir um racionalismo que respeite as exigências da ciência, como polo de demonstração e, ao mesmo, tempo de prova, aberto a correntes divergentes e não reducionistas. Nessa mesma perspectiva, Pourtois e Desmet (1997, p. 2) defendem que "em face da diversidade das correntes, pensamos que é altamente útil examinar as divergências que constituem as diferentes facetas do conhecimento nas ciências humanas". Assim, justifica-se a necessidade da interdisciplinaridade associada à pluralidade, ou seja, métodos se completando, teorias se debatendo, diferentes abordagens se confrontando sistematicamente, em alguns casos somando, em outros subtraindo, dividindo ou multiplicando.

Como visto anteriormente, a complexidade reapareceu de maneira marginal a partir da cibernética e da teoria da informação. Para alguns pesquisadores, a palavra "complexidade" associada ao respectivo paradigma ainda é sinônimo de complicação, de emaranhado. Mas o que fica claro é que esse conhecimento não se reduz a uma mera complicação: ele é profundo e apareceu por diversas vezes na história da filosofia. A complexidade se traduz no problema da dificuldade de pensar, uma vez que o pensamento é um combate com ele próprio, com e contra a lógica, com e contra as palavras, com e contra os conceitos. Por muito tempo, o conhecimento científico centrou-se em dois fundamentos, na tentativa de simplificar a realidade: a objetividade dos enunciados científicos estabelecidos a partir de verificações empíricas e a coerência lógica das teorias que se fundavam nesses dados obtidos a partir de experimentos empíricos. Depois que a epistemologia anglo-saxã redescobriu, por volta dos anos 1950 e 1960, que nenhuma ciência poderia se pretender absoluta, uma teoria científica passou a ser sinônimo de incerteza e de algo inacabado.

Uma vez abandonada essa visão ingênua de que uma teoria é o reflexo idêntico de uma dada realidade, cedese lugar à ideia de que ela é sobretudo um sistema de ideias ou apenas uma forma de conceber a realidade. Um sistema de ideias obedece a princípios lógicos, mas tem por trás de si próprio princípios ocultos, chamados aqui de paradigmas. Tanto teorias como sistemas de ideias ou paradigmas são produto de uma dada cultura, e isso remete ao conceito de epistemologia. Por essa razão, a divisão do conhecimento em disciplinas, amplamente criticada pela complexidade, inviabiliza o conhecimento do conhecimento, uma vez que, em cada parte do todo, existe outra parte desconhecida. Nesse sentido, o progresso do conhecimento levaria então, também, ao progresso do desconhecimento. A partir disso, compreende-se por que Morin sugere que "conhecer é uma aventura incerta, frágil, difícil, trágica" (MORIN, 1996, p. 33).

Embora tardia e ainda em construção, a análise epistemológica dos conhecimentos produzidos no campo da Administração vem se desenvolvendo com vigor. Prova disso é a identificação e a discussão dos paradigmas que comportam as teorias organizacionais. Nesse sentido, fazem-se aqui breves menções a duas dessas análises: a primeira, elaborada por Burrel e Morgan em 1979, e a segunda, proposta por Chanlat e Séguin em 1983.

A partir do mapeamento que abrange o campo dos Estudos Organizacionais desenvolvido por Burrel e Morgan (1979) e que estabeleceu quatro paradigmas (funcionalista, humanista radical, estruturalista radical e interpretacionista), fica claro que dois deles são de abordagem subjetivista: o interpretacionista e o humanista radical, enquanto o funcionalista e o estruturalista radical têm abordagem objetivista. Para os autores, a oposição paradigmática é clara, como, por exemplo, a comparação entre o paradigma interpretacionista e o funcionalista.

O paradigma interpretacionista questiona o objetivismo do funcionalismo e se propõe buscar sua superação. Enquanto para os funcionalistas as organizações são objetos tangíveis, concretos e objetivos, ou seja, de abordagem instrumentalista, os interpretacionistas veem as organizações como processos que surgem das ações intencionais do ser humano, individualmente ou em harmonia com outras intenções. Para esse segundo grupo, a realidade social se constitui de uma rede de representações complexas e subjetivas, uma vez que essas diversas intenções interagem para interpretar o mundo e dar sentido a ele (VERGARA; CALDAS, 2005).

Peci (2006), em um estudo crítico sobre a teoria neoinstitucional, destaca que, ao identificar os processos de interação entre as organizações no campo organizacional como conscientes, fica evidente o distanciamento entre essa perspectiva e o construtivismo social, que se dá no nível inconsciente (BERGER; LUCKMANN, 2001). Da mesma forma, a autora observa que os próprios Powell e DiMaggio (1990), representantes do neoinstitucionalismo, reconhecem a falha que ele traz ao apresentarem a teoria da estruturação de Giddens como base da macroanálise institucional, enfocando, todavia, variáveis reificadas em campos organizacionais e ignorando os processos de institucionalização que originaram essas mesmas variáveis 
(instituições). Assim, Peci (2006) deduz que, na prática, o neoinstitucionalismo não consegue se livrar da ortodoxia funcionalista dos estudos organizacionais. Como afirmam Hasselbladh e Kallinikos (2000), a legitimidade como difusora de padrões é vista como requisito para o sucesso, não se distanciando da concepção tradicional adaptativa e funcionalista das organizações. Isso pouco difere da base conceitual funcionalista de Parsons (1967), que desde os anos 1960 já destacava a necessidade de os sistemas sociais se adaptarem a valores e normas mais gerais.

Apesar da grande difusão do trabalho de Burrel e Morgan (1979), algumas manifestações contrárias se fazem presentes, como a de Deetz (2000), que critica as dimensões escolhidas e a análise filosófica subjacente. Uma das críticas feitas relaciona-se justamente à aceitação por Burrel e Morgan da dicotomia objetivo/subjetivo, contribuindo para a sua polarização. O trabalho de Latour (1994), que adota a perspectiva da teoria ator-rede, pode ser considerado um exemplo de ruptura com a modernidade, eliminando a dicotomia entre elementos humanos e não humanos ou objetivos e subjetivos de suas análises, negando a distinção entre os quadrantes de Burrel e Morgan.

Chanlat e Séguin (1983) propõem outra grade analítica para o exame dos paradigmas nas teorias organizacionais. Sua proposta comporta dois paradigmas - o funcionalista e o crítico - os quais abrigam diversas correntes internas. Os paradigmas se opõem, principalmente ao conceberem, cada um ao seu modo, a natureza da organização: enquanto o funcionalista adota a concepção sistêmico-sincrônica, teleológica, não histórica, harmônica e integrativa, o paradigma crítico baseia-se nas concepções sociológica, dialética, histórica, desmistificadora, "acionalista" e emancipadora. Voltaremos a esta proposta mais tarde.

Num estudo publicado em 1992, Serva indica alguns temas a serem explorados nos estudos sobre organizações com base na epistemologia da complexidade: 1) o enriquecimento da percepção da relação ambiente-organização, ampliando o conhecimento sobre a construção da identidade organizacional e revelando com mais clareza as formas de influência das organizações sobre o ambiente; 2) a compreensão da "contraprodutividade", com base na análise dos distúrbios do funcionamento interno dos sistemas autoprodutores, como alternativa à opção pela análise tradicional das disfunções da burocracia; 3) nas teorias da administração pública, o emprego da lógica paradoxal e da discussão do binômio autonomia-dependência na análise da relação entre as esferas pública e privada que marcam o cotidiano das organizações e empresas públicas; 4) a consideração da "desordem" (ruídos, eventos inesperados, crises, conflitos etc.) como dimensão inegável das organizações, aperfeiçoando os conhecimentos sobre mudanças organizacionais e evitando o reducionismo do recurso único à abordagem da mudança planejada; 5) a análise das organizações da economia social, do terceiro setor, ou ainda das organizações "alternativas" e "coletivistas", cuja realidade é marcada pela confluência de racionalidades e lógicas opostas, como a lógica do mercado e a lógica da solidariedade.

Retornando ao estudo de Chanlat e Séguin (1983), destaca-se a indicação do emprego da epistemologia da complexidade nos estudos organizacionais e na própria epistemologia da administração. Os autores, ao considerarem o paradigma funcionalista como tributário da ordem social dominante, consideram, inversamente, o paradigma crítico como o paradigma da "desordem". Numa visão ousada e complexa de complementaridade, é incentivada a adoção de ambos os paradigmas na análise organizacional.

A consideração de ambos os paradigmas na análise organizacional é endossada por Benson (1987, p. 425). $\mathrm{O}$ autor relaciona o funcionalismo e o positivismo à "pesquisa morfológica" na administração, ao passo que relaciona a perspectiva dialética ao paradigma crítico. Ao criticar o funcionalismo, afirma que "isto não significa que a pesquisa morfológica não tem valor. Ao contrário, a descrição das regularidades é uma etapa necessária em toda trilha dialética. Ela deve, entretanto, ser integrada a um esquema explicativo mais amplo". Entretanto, a missão de definir os parâmetros do campo de pesquisa não deve ser deixada unicamente aos estudos morfológicos, tendo em vista seu caráter limitado (BENSON, 1983, p. 425).

Dentre as contribuições potenciais da epistemologia inerente ao paradigma da complexidade para a epistemologia da administração e a teoria das organizações, entende-se que a adoção de paradigmas da ordem e de paradigmas da desordem numa perspectiva de complementaridade seria, ao mesmo tempo, a maior contribuição e o seu maior desafio. Empregar conceitos como autopoiese, auto-organização, evento, ordem-desordem, dentre outros e, principalmente, empregar a lógica dialética do paradigma da complexidade (numa visão crítica) sem descartar totalmente os aspectos do paradigma funcionalista implica um enorme desafio intelectual para os pesquisadores. Implica, sobretudo, estar sempre vigilante para o risco da impropriedade epistemológica. Todavia, adotar o paradigma emergente não significaria, em última instância, correr riscos?

Tomando como alerta a compreensão de Prigogine e Stengers (1997) de que a transformação das ciências contemporâneas não deve ser entendida como ruptura, depreende-se que não há um mundo finalizado e estático; há um 
mundo a ser explorado da história dos homens, das sociedades e dos seus saberes. Quando esses autores se referem à "nova aliança" estão falando o mesmo que Morin (1982, 1986, 1996) quando este discute o "anel epistemológico" para mostrar a utilidade de uma epistemologia complexa, referindo-se à contribuição do conhecimento do conhecimento para o progresso do próprio conhecimento. Dito de outra forma, Morin, Prigogine e Stengers utilizam-se de termos diferentes para tratar de uma mesma concepção. Mas ao trazer para a epistemologia da administração e para a teoria das organizações o que Morin chama de "ciência nova" e Souza Santos (1988) de "paradigma emergente", é preciso cuidar para que os pressupostos do pensamento complexo permeiem tal concepção. Parafraseando Souza Santos (1988), os temas fluem de várias fontes e de várias direções para se encontrar em galerias onde se juntarão para dar conta da realidade social.

\section{CONSIDERAÇÕES FINAIS}

O objetivo deste ensaio foi apresentar uma reflexão acerca da epistemologia da complexidade e seu uso em pesquisa social, mais especificamente na teoria das organizações, no momento em que se constata o avanço da epistemologia da administração.

Apesar da necessidade premente de desenvolver teorias que tentem explicar o fenômeno organizacional de uma forma mais complexa e profunda, a grande maioria das pesquisas desenvolvidas na área ainda apresenta métodos tradicionais de orientação positivista e funcionalista, conforme pesquisa realizada por Vergara e Peci (2003) em três revistas estrangeiras e três brasileiras, todas de grande reputação. Os resultados da pesquisa das autoras mostram a necessidade de reflexão sobre as suas possíveis causas. Um fato a destacar é a questão relacionada com a política institucional de construção de conhecimento. Para as autoras, o pós-modernismo tem ajudado a mostrar que essa relação não é nem determinada por imperativos estruturais nem por uma ordem maior de autoridade ou poder. Os pesquisadores acabam reféns da própria linguagem (CALAS; SMIRCICH, 1999) e dos jogos do poder nela incorporados; consequência de um discurso há anos institucionalizado. Assim, o status do pesquisador e os paradigmas tradicionais subjacentes ao modo de fazer ciência também perpetuam o conhecimento adquirido. Nesse sentido, as questões de poder na academia acabam por influenciar as opções dos autores, e o contexto social e cultural em que estão submersos é que dirige suas escolhas, fazendo com que sejam distintas entre si. Assim, a metodologia relaciona-se com a forma como o pesquisador percebe o mundo e o ser (BERGER e LUCKMANN, 2001).

No caso da teoria das organizações, um olhar sobre a organização como sistema epistemológico e sobre a capacidade de os pesquisadores identificarem os pontos cegos das teorias atualmente utilizadas pode ser um exemplo da tentativa de um avanço epistemológico, conforme defendia Guerreiro Ramos com sua abordagem substantiva. Poderia a utilização da epistemologia que baseia o paradigma da complexidade se constituir também numa forma de avanço para a epistemologia da administração e para as teorias organizacionais?

A ciência não é dogma e está repleta de contradições, dúvidas e reflexões. E, enquanto parte do conhecimento, ela, a ciência, apresenta-se como um processo dinâmico que acaba evidenciando a limitação de pesquisadores $e$ cientistas, haja vista a limitação em se dar conta dela. A complexidade requerida acerca das colocações que aqui foram feitas toma a mente, levantando várias questões para a continuidade e o aprofundamento do debate, inclusive questões relativas à maneira de evitar a impropriedade epistemológica. Ao se estudar a complexidade e sua possível contribuição para a mitigação dos pontos cegos da teoria organizacional vigente, pergunta-se: quais as bases epistemológicas dos trabalhos que vêm sendo publicados no campo da Administração sobre complexidade? Desenvolver o pensamento complexo passa necessariamente pela inclusão na comunidade do paradigma interpretacionista? Quais as implicações da adoção simultânea de paradigmas divergentes? Com o emprego do paradigma da complexidade, numa perspectiva crítica do fenômeno organizacional, até que ponto e sob quais aspectos específicos é possível utilizar recursos do paradigma funcionalista? Compreender esses questionamentos e agir sobre eles passa a ser, pelo menos para os autores deste ensaio, uma trajetória necessária para a tomada de consciência acerca da complexidade dos estudos organizacionais, visando contribuir para o avanço da reflexão epistemológica no campo da Administração.

\section{NOTA DA REDAÇÃo}

Artigo originalmente apresentado no EnANPAD 2009 e submetido à RAE em regime de fast-track.

\section{REFERÊNCIAS}

AUDET, M; DÉRY, R. La science réfléchie. Quelques empreintes de l'épistémologie des sciences de l'administration. Anthropologie et Sociétés, v. 20, n. 1,1996 
BENSON, J. K. Les organisations: un point de vue dialectique. In: SÉGUIN, F; CHANLAT, J. F. (Orgs) L'analyse des organisations: une anthologie sociologique. Montréal: Gaëtan-Morin, 1983.

BERGER, P. L; LUCKMANN, T. A construção social da realidade. Petrópolis: Vozes, 2001

BERTHELOT, J. As ciências do social. In: BERTHELOT, J. (Org) Épistémologie de sciences sociales. Paris: PUF, 2001.

BURRel, G; MORGAN, G. Part 1: In search of a framework - 1. Assumptions about the nature of social science; 2 . Assumptions about the nature of society. In: BURREL, G; MORGAN, G. Sociological paradigms and organizational analysis. London, 1979.

CALAS, B; SMIRCICH, L. Do ponto de vista da mulher: abordagens feministas em estudos organizacionais. In: CLEGG, S. R; HARDY, C; NORD, W. R. (Orgs) Handbook de estudos organizacionais, v. 1. São Paulo: Atlas, 1999.

CAMPOS, A. M. Contribuição para o resgate da relevância do conhecimento para a administração. In: SEMINÁRIO EM BUSCA DE NOVOS CAMINHOS PARA AS ORGANIZAÇÕES. Rio de Janeiro: Coppead, 1993.

CHANLAT, J-F; SÉGUIN, F. (Orgs) L'analyse des organisations: une anthologie sociologique. Montréal: Gaëtan-Morin, 1983.

CHEVALLIER, J; LOSCHAK, D. A ciência administrativa. Mem Martins: Europa-America, 1980.

DEETZ, S. Conceptual foundations. In: JABLIN, R. F; PUTNAM, L. L. (Eds) The New Handbook of Organizational Communications: Advances in Theory, Research, and Methods. Thousand Oaks, CA: Sage Publications, 2000

DEMO, P. Metodologia científica em ciências sociais. São Paulo: Atlas, 1985.

DESCAMPS, C. A Complexidade. In: As ideias filosóficas contemporâneas na França (1960-1985). Rio de Janeiro: Jorge Zahar, 1991.

GARCIA, F. C; BRONZO, M. As bases epistemológicas do pensamento administrativo convencional e a crítica à teoria das organizações. In: ENCONTRO DE ESTUDOS ORGANIZACIONAIS DA ASSOCIAÇÃO NACIONAL DE PÓS-GRADUAÇÃO E PESQUISA EM ADMINISTRAÇÃO, 1, 2000, Curitiba. Anais. Curitiba: ANPAD, 2000.

GUERREIRO RAMOS, A. A nova ciência das organizações: uma reconceituação da riqueza das nações. São Paulo: FGV, 1989.

HASSELBLADH, H; KALLINIKOS, J. The Project of rationalization: a critique and reappraisal of neo-institutionalism in organizational studies. Organization Studies, v. 21, n. 4, p. 697-720, 2000.

JAPIASSU, H. Introdução ao pensamento epistemológico. 6. ed. Rio de Janeiro: Francisco Alves, 1991.

KUHN, T. A estrutura das revoluções científicas. São Paulo: Perspectiva, 1987.

LATOUR, B. Jamais fomos modernos: ensaio de antropologia simétrica. São Paulo: Editoria 34, 1994.
MORGAN, G. Imagens da organização. São Paulo: Atlas, 1996.

MORIN, E. O método IV. As ideias: a sua natureza, vida, habitat e organização. Lisboa: Europa-América, 1991.

MORIN, E. Ciência com consciência. Lisboa: Europa-América, 1982.

MORIN, E. Complexidade e organização. In: AUDET, M; MALOUIN J (Orgs) La production des connaissances scientifiques de l'administration. Québec: Les Presses de l'Université Laval, 1986.

MORIN, E. O problema epistemológico da complexidade. Lisboa: EuropaAmérica, 1996.

PARSONS, T. Sugestões para um tratado sociológico da teoria da organização. In: ETZIONI, A. (Org) Organizações complexas. São Paulo: Atlas, 1967.

PECI, A. A nova teoria institucional em estudos organizacionais: uma abordagem crítica. Cadernos Ebape, IV, 2006.

POURTOIS, J-P; DESMET, H. Épistémologie et instrumentation en sciences humaines. Sprimont: Mardaga, 1997.

PRIGOGINE, I; STENGERS, I. A nova aliança: a metamorfose da ciência. 3. ed. Brasília: Editora da UnB, 1997.

SERVA, M. O paradigma da complexidade e a análise organizacional. RAErevista de administração de empresas, v. 32, n. 2, p. 26-35, 1992.

SERVA, M. Abordagem substantiva e ação comunicativa: uma complementaridade proveitosa para a teoria das organizações. Revista de Administração Pública, v. 31, n. 2, p. 108-34, 1997a.

SERVA, M. A racionalidade substantiva demonstrada na prática administrativa. RAE-revista de administração de empresas, v. 37, n. 2, p. 18-30, 1997b.

SERVA, M. O fato organizacional como fato social total. Revista de Administração Pública, v. 35, n. 3, p. 131-152, 2001.

VARELA, F. Autonomie et connaissance. Paris: Seuil, 1989.

VERGARA, S; CALDAS, M. P. Paradigma interpretacionista: a busca da superação do objetivismo funcionalista nos anos 1980 e 1990. RAE-revista de administração de empresas, v. 45, n. 4, p. 66-71, 2005.

VERGARA, S; PECI, A. Escolhas metodológicas em estudos organizacionais. Organizações \& Sociedade, v. 10, n. 27, p. 13-26, 2003. 